\title{
TOWARD OPTIMUM CONFIGURATION OF CIRCUMFERENTIAL GROOVE CASING TREATMENT IN TRANSONIC COMPRESSOR ROTORS
}

\author{
Chunill HAH \\ NASA Glenn Research Center, \\ MS 5-11, Cleveland, Ohio 44135
}

\begin{abstract}
The current paper first reviews experimental and numerical investigations to understand flow physics and to develop optimum configurations of circumferential grooves in compressor rotors. Circumferential grooves are used mainly to increase stall margin in axial compressors with small decrease in aerodynamic efficiency. Although circumferential groove casing treatment has been used widely, flow mechanisms of the circumferential grooves at near stall conditions are not well understood yet. Detailed time-dependent flow measurement inside tip gap in a high speed compressor is still a big challenge even though significant advance has been made in non-intrusive flow measurement technique. Therefore numerical approaches have been used to study relevant flow physics. However, optimum design of circumferential grooves to a given compressor with the computational tools is not practical yet. In the present paper, various investigations to study flow physics of circumferential groove casing treatment in axial compressor are reviewed first. Possible missing flow physics are identified and future research efforts for the optimum design are discussed.
\end{abstract}

\section{INTRODUCTION}

A variety of casing treatments have been applied to extend the operating range of various compressors (Smith and Cumpsty [1985], Lee and Greitzer [1990], Moore et al. [1971], Prince et al. [1974], Fujita and Takata [1985], Paulon and Dehoudt [1982], Van de Wyer et al. [2010], Chen et al. [2010], and Mueller et al. [2011]). Most previous experimental studies indicate that casing treatments, which are more effective in delaying stall, tend to induce additional aerodynamic loss at peak efficiency conditions.

Circumferential groove casing treatment has been applied both for subsonic and transonic compressors. Although it is generally believed that the circumferential grooves on the compressor casing do suppress stall inception, the fundamental flow mechanisms are not well understood. Furthermore, the design criteria of the circumferential grooves are mainly based on loosely connected experimental data from subsonic compressors and their validity on transonic compressor is not clear. Most of the previous studies were aimed at obtaining changes in the overall compressor performance data. Mueller et al. [2011] applied Particle Imaging Velocimetry (PIV) to measure detailed steady flow field near and inside circumferential grooves in an axial transonic compressor stage.

With the advance of CFD technology, several attempts have been made to investigate the effects of casing treatments on compressor performance (Crook et al. [1993], Hall et al. [1996], Rabe and Hah [2002]). Paulon and Dehoudt [1982] conducted a theoretical investigation of the effects of circumferential grooves. Rabe and Hah [2002] investigated circumferential grooves applied to the first stage rotor in a modern highly loaded two-stage transonic axial compressor. They found that the local flow incidence near the pressure side of the leading edge is reduced due to the circumferential grooves. Mueller et al. [2007] investigated various circumferential grooves applied to the rotor in a single stage transonic compressor.

Circumferential grooves extend flow range for most compressors although cases with no benefits have also been reported. The primary purpose of the circumferential grooves is to alter flow structure near the compressor casing as the compressor operates toward stall limit. The precise steady and/or unsteady flow physics at stall onset is not well understood even for the compressor without any casing treatment. Therefore, the underlying flow physics of the circumferential grooves at near stall operation are not clearly understood either. Experimental and numerical studies to investigate aerodynamics of circumferential grooves and design optimization are first reviewed. Most previous numerical studies are based on the steady Renolds-averaged Navier-Stokes(RANS) approach. Although the steady RANS approach calculates some effects of the circumferential grooves on the stall margin, measured increase in stall margin is not well calculated. The flow field in a compressor becomes significantly unsteady at near stall operation. Therefore unsteady flow effects should be considered for the circumferential grooves. Unsteady flow effects on the circumferential groove casing treatment are examined by the Large Eddy Simulation. 


\section{PREVIOUS EXPERIMENTAL AND NUMERICAL INVESTIGATIONS ON CIRCUMFERENTIAL GROOVE CASING TREATMENT}

Circumferential grooves have been studied since early 1970 as a part of passive flow control devices in compression system. Experimental methods were mainly applied in early days as reliable analytical tools were not available yet. Based on test data with limited variation of configuration, rough design guidance was established. Most experimental data have shown that the circumferential grooves extends compressor stall margin with relatively minor aerodynamic penalty. In the following section, three recent studies that combine both experimental and numerical methods are reviewed.

\section{AFRL TWO STAGE TRANSONIC COMPRESSOR}

Rabe and Hah [2002] studied effects of circumferential grooves on a two-stage transonic axial compressor. Detailed numerical study was conducted to investigate flow mechanism of circumferential grooves. A steady RANS method was applied for the study. The numerical results showed increased stall margin with the circumferential grooves as the measurement shows. The agreement between the numerical simulation and the measurement was reasonable in qualitative sense.

Various casing treatments were installed and tested on the first rotor. Table 1 shows aerodynamic performance of the rotor 1. This study investigated three different groove configurations, shown in Fig. 1, in comparison with a smooth wall. Since the largest variation in the stall margin occurred near $83 \%$ speed, this speed was chosen to present the comparison of the casing configurations. The grooves lie between $15 \%$ and $55 \%$ of the blade axial chord. All of the grooves in a given configuration have the same shape. The first configuration is relatively conventional, with five grooves at a depth of $20.32 \mathrm{~mm}$. A second configuration, with shallow grooves of $1.25 \mathrm{~mm}$, is used to examine the influence of groove depth, commonly believed to be the most significant parameter (Paulon and Dehondt [1982]). A third configuration uses only the two most upstream grooves of the second configuration.

The measurements indicate that the first set of circumferential grooves extend the flow range by roughly $10 \%$ from the original smooth wall case. The numerical simulation also indicated the increase of stall margin. For high speed compressor with this level of pressure rise is very difficult to operate through stall point and the measurement of stalling flow rate is not always precise. As a steady Reynolds-averaged Navier-Stokes(RANS) approach was applied for the numerical simulation, any possible unsteady flow effects at near stall operation was not considered in the numerical simulation.

Following possible effects due to circumferential grooves were examined.

1. Two-dimensional boundary layer effects.

2. Tangential velocity effects.

3. Endwall boundary layer effects.

4. Segmentation of the tip-clearance vortex.

Based on the numerical simulation, the authors found two-dimensional effects alter the flow structures most. The blade boundary layers near the tip can move into and out of the grooves. Flow into the grooves acts as boundary layer bleeding, and flow out of the grooves acts like impingement on the boundary layer, which might have a beneficial effect on the endwall flow field.

Figure 2 shows contours of the radial velocity component at the blade tip section. The bleeding of the pressure side boundary layer into the grooves is seen to be roughly proportional to the depth of the grooves. However, the impingement of flow from the groove into the suction surface boundary layer is not strongly dependent on the groove depth. Both measurement and numerical simulation showed that the shallow grooves extend the operating range as much as the deep grooves for this compressor. The impingement of flow into the suction surface boundary layer might play dominant role for this configuration. Aerodynamic loading at the blade tip is shown in Figure 3. It is interesting to see that the loading is reduced with the grooves, which indicates less tip clearance flow across the blade tip. Figure 4 compares tip clearance vortex structure at the mass flow rate where the rotor with smooth casing operates just before stall. Circumferential grooves configuration reduces the tangential penetration of tip clearance vortex and the vortex core strength, which indicates further stable operation beyond the current mass flow rate. Changes in tip vortex structure in this compressor are caused by the impingement of flow from the grooves and reduced loading at the blade tip section.

\section{DARMSTADT SINGLE STAGE TRANSONIC COMPRESSOR}

Since 1994, a series of axial single stage transonic compressors have been designed and tested for various research programs at the Technical University of Darmstadt (see Figure 5).

The design parameters of the high-speed test rig represent a front stage of typical commercial HPCs. The rig has been built for validation of design tools and CFD codes. It also functions as an experimental test bed for new materials and manufacturing methods such as blisks and CRP. Many different rotors have been tested. The test facility operates in an open circuit; ambient air is sucked into a settling chamber and through a calibrated bell mouth into the stage. Due to the length of the inlet duct and the small volume established at the stage outlet, stall can occur but surge cannot.

The rotor used for the circumferential casing treatment is the Darmstadt Rotor-1 titanium blisk with 16 radially stacked CDA-profiles. Table 2 shows the Rotor- 1 geometries and the compressor characteristics at design conditions.

Four different casing inserts were manufactured, each representing another configuration of circumferential grooves. The groove onset downstream of the leading edge is at $15.25 \%$ of the projected axial chord. Compressor casing with 6 deep grooves are shown in Figure 6. Details of the all the grooves are given by Mueller et al. [2007]. Figure 7 shows total pressure rise with various grooves along with the 
numerical simulation. For this compressor, 6 deep grooves increased the stall margin most. Therefore, numerical simulations with the 6 deep grooves were performed with the steady Reynolds-Averaged Navier-Stokes Approach. Figure 8 shows calculated velocity vectors inside tip clearance and grooves with 6 deep grooves at the mass flow rate where the compressor with smooth casing operates just before stall. Corresponding tip vortex structure is shown in figure 9 in terms of particle traces. Figure 10 shows tip vortex structure with smooth wall at the same mass flow rate. The vortex structures in Figures 9 and 10 indicates that the core vortex strength is weaker than that of the smooth wall and the tip clearance vortex does not penetrate into the blade passage as much as that with the smooth casing, which was also observed in the previous study of AFRL Compressor. The steady RANS simulation shows that the operating range is extended due to the circumferential grooves as the measurement shows. The steady RANS calculates the stalling mass flow rate very close to the measured value for the smooth casing. However, steady RANS calculates about $15 \%$ increase in stall margin with the circumferential grooves while the measurement shows almost $20 \%$ increase.

\section{NOTRE DAME SINGLE STAGE TRANSONIC COMPRESSOR}

Chen et al. [2010] investigated numerically circumferential groove casing treatment in the transonic axial compressor at the Notre Dame University. The cross section of the compressor is shown in Figure 11. The casing treatment with 7 circumferential grooves is given in Figure 12. The effects of the circumferential grooves on the compressor speed curves are shown in figure 13. Like a previous study on the Darmstadt's compressor, the steady RANS captures stall margin with the smooth wall reasonably well. However, the calculated extension of stall margin with the grooves is about $70 \%$ of the measured increase of the stall margin. Changes in tip vortex structure are shown in Figure 14. Again, similar changes in tip clearance vortex structures due to the casing grooves are observed like the previous two studies.

Steady RANS simulations show effects of circumferential grooves which are similar to the measured values on the flow field near the rotor tip for the three compressor stages described in this section. As mentioned earlier, precise measurement of stall point in high speed compressor is very difficult. On the other hand, numerical procedure to predict compressor stall point with the steady RANS is not validated adequately. With the steady RANS, the mass flow rate is decreased by increasing exit pressure untill a stable numerical solution can not be obtained to determine stall point. The numerical stall point depends on computational grid as well as applied turbulence model. Various studies indicate that the steady RANS calculates some averaged flow features reasonably well at near stall operation. Previous numerical studies indicate that the steady RANS calculates the stalling mass flow rate reasonably well. However, the steady numerical simulation does not calculate the extended stall margin due to casing groove treatment properly. In the following section, flow structure at near stall condition is further examined and possible effects of flow unsteadiness is examined.

\section{UNSTEADY FLOW EFFECTS ON THE PERFORMANCE OF CIRCUMFERENTIAL GROOVES}

Most numerical simulations on the effects of circumferential grooves have been based on the steady RANS approach(Rabe and Hah [1992], Mueller et al.[2007], Shabbir and Adamczyk [2005], Van De Wyer et al. [2010], and Chen et al. [2010]). These numerical simulations based on the steady RANS show overall trend of measured aerodynamic benefits of the grooves. However, the steady simulation does not seem to calculate all the measured increase in stall margin as shown in Figures 7 and 13. This might be due to the fact that steady RANS does not capture all the effects of the circumferential grooves on the main passage flow. Flow structures at near stall are briefly examined first. Then, possible effects of flow unsteadiness on the performance of the circumferential grooves are examined in this section. Figure 15 shows changes in instantaneous pressure distribution at near stall operation on the casing from a high frequency pressure measurement in the Darmstadt's transonic compressor stage (Bergner et al. [2006]). Fig. 15 shows significant changes in pressure distribution and tip vortex trajectory. This unsteadiness is mainly due to interaction between the tip clearance vortex and the passage shock. The measurements indicate that the tip vortex is highly intermittent as the pressure difference across the blade tip section changes.

To include possible effects of unsteady nature of flow field at near stall operation, unsteady flow simulation was performed at several operation points with the deep 6 groves configuration of the Darmstadt's transonic rotor. Large Eddy Simulation (LES) was applied to represent tip vortex oscillation and vortex/passage-shock interaction more realistically. Details of the applied LES procedure are given by Hah et al. [2010]. 40 computational nodes are used in radial direction to describe the grooves. The total computational was 194 nodes in the blade-to-blade direction, 168 in the spanwise direction and 480 nodes in the streamwise direction for a single blade passage. Calculated compressor pressure rise characteristics from the LES simulations are shown in Figure 16. The unsteady LES simulation calculates further extension of the operating range than the RANS steady simulation, which agrees well with the measurement. The results shown in Figure 16 indicate that there are significant influences of unsteady flow on the performance of the circumferential grooves. This explains why various steady RANS numerical simulations can not calculate stall margin increase accurately. Figure 17 shows changes of static pressure at the blade tip section during one rotor passage cycle. As shown in Figure 17, the pressure field changes significantly during one passage cycle. Therefore, flow impingement from the circumferential grooves also changes and the circumferential grooves 
provide unsteady flow injection into the main passage. The unsteady injection of flow with axial and radial momentum provides additional increase in the stall margin. When this unsteady injection is dominant mechanism, the steady RANS can not calculate any improvement in stall margin with the circumferential grooves while the actual measurement shows significant increase in stall margin. Fig 18 shows changes in the velocity vectors near the casing at $10 \%$ pitch from the pressure side. Changes in radial velocity near the casing are shown in Figure 19.

As the flow field becomes more oscillatory at near stall operation, the unsteady injection effects becomes dominant factor of the circumferential grooves. Therefore, unsteady effects should be properly considered when any optimization strategy are pursed based on numerical simulations. Steady RANS can not be successfully applied for such applications.

\section{CONCLUDING REMARKS}

Various previous studies on circumferential groove casing treatment on the stall margin in a transonic compressor rotor are reviewed. Steady RANS approach has been applied to investigate detailed flow mechanisms due to the circumferential grooves as the experimental investigations do not provide detailed flow structure. Although steady RANS seem to calculate some qualitative trends correctly, the method does not seem to calculate measured increase of stall margin properly. The present investigation shows that the flow field becomes unsteady as the compressor operates toward stall. Unsteady flow injection from the grooves with axial and radial momentum into the main flow near the casing is a main mechanism to enhance flow stability and increased stall margin. For certain design of compressors, unsteady effects might be the dominating factor and steady RANS might not calculate any benefits due to the circumferential grooves. For any optimization strategy of the casing treatment with the numerical flow analysis tools, unsteady effects should be properly included.

\section{ACKNOWLEDGMENTS}

The author gratefully acknowledge the support of this work by the NASA Fundamental Aeronautics program, Subsonic Fixed Wing project.

\section{REFERENCES}

Bergner, J., Matthias, K., Schiffer, H. P., and hah, C., 2006,

"Short length-Scalr Rotating Stall inception in a

Transonic Axial Comrpressor- Experimental

Investigation," ASME Paper GT2006-90209.

Chen, H., Huang, X., Shi k., Fu, S., Bennington, M.A., Morris S.C., Ross M., McNulty, S., and Wadia, A., 2010, “A CFD Study of Circumferential Groove Casing Treatments in a transonic Axial Compressor," ASME Paper GT2010-23606.

Crook, A. J., Greitzer, E. M., Tan, C. S., and Adamczyk, J. J., 1993, "Numerical Simulation of Compressor Endwall and Casing Treatment Flow Phenomena," ASME Journal of Turbomachinery, Vol.115, No.3, pp.501-512.
Fujita, H. and Takata, H., 1985, "A Study of Configurations of Casing Treatment for Axial Flow Compressors," Bull. of JSME, Vol. 27, No. 230, pp. 1675-1681.

Hah, C., Voges, M., Mueller, M. W., and Schiffer, H. P., 2010, "Characteristics of Tip Clearance Flow Instability in a Transonic compressor," ASME Paper GT-201022101.

Hall, E. J., Heidegger, N. J., and Delaney, R. A., 1996, "Performance Prediction of Endwall Treated Fan Rotors with Inlet Distortion," AIAA Paper AIAA 96-0244.

Lee, N. K. W. and Greitzer, E. M., 1990, "Effects of Endwall Suction and Blowing on Compressor Stability Enhancement", ASME Journal of Turbomachinery, Vol. 122, pp. 133-144.

Moore, R. D., Kovich, G., and Blade, R. J., 1971, "Effect of Casing Treatment on Overall and Blade-Element Performance of a Compressor Rotor", NASA TN D6538.

Mueller, M. W., Schiffer, H. P., and Hah, C., 2007, "Effects of Circumferential Grooves on the Aerodynamic Performance of an Axial Single-Stage Transonic Compressor," ASME Paper GT-2007-27365.

Mueller, M. W., Schiffer, H. P., Voges M. and Hah, C., 2011, "Investigation of Passage Flow Features in a Transonic Compressor Rotor with Casing Treatments," ASME Paper GT-2010-45364.

Paulon, J. and Dehondt, D., 1982, "Influence of Casing Treatment on the Operating Range of Axial Compressors," ASME Paper 82-GT-103.

Prince, D. C., Jr., Wisler, D. C., and Hilvers, D. E., 1974, "Study of Casing Treatment Stall Margin Improvement Phenomena," NASA CR-134552.

Rabe, D. C. and Hah, C., 2002, "Application of Casing Circumferential Grooves for Improved Stall Margin in a Transonic Axial Compressor," ASME Paper GT-200230641.

Shabbir. A. and Adamczyk,J.,J., 2005, "Flow Mechanism for Stall Margin Improvement due to Circumferential Casing Grooves on Axial Compressors," ASME Journal of Turbomachinery, Vol. 127, October 2005,pp.708-717.

Smith, G. D. J. and Cumpsty. N. A., 1985, "Flow Phenomena in Compressor Casing Treatment", ASME Journal of Engineering for Gas Turbines and Power, Vol. 117, pp. 532-541

Van de Wyer, N, Desset, F. B., Brouckaet, J F., Thomas, J-F. and Hiernaux, S., 2010, "Experimental Investigation of the Steady and Unsteady Flow Field in a Single Stage Low Pressure Axial Compressor with a Circumferential Groove Casing Treatment," ASME Paper GT201023474 . 
Table 1 Aerodynamic Performance of the Rotor

\begin{tabular}{|l|c|}
\hline \multicolumn{1}{|c|}{ Parameter } & Value \\
\hline Design pressure ratio & 2.5 \\
\hline Design air flow, kg/sec & 71.8 \\
\hline Tip clearance at 83\% speed, cm & .089 \\
\hline Tip speed at 83\% speed, m/sec & 339.8 \\
\hline $\begin{array}{l}\text { Baseline air flow at 83\% speed, } \\
\text { peak efficiency, kg/sec }\end{array}$ & 59.65 \\
\hline $\begin{array}{l}\text { Baseline pressure ratio at 83\% speed, } \\
\text { peak efficiency }\end{array}$ & 1.89 \\
\hline Mass flow measurement precision, \% & \pm 0.18 \\
\hline Pressure ratio measurement precision, \% & \pm 0.14 \\
\hline Efficiency measurement precision, \% & \pm 0.12 \\
\hline
\end{tabular}
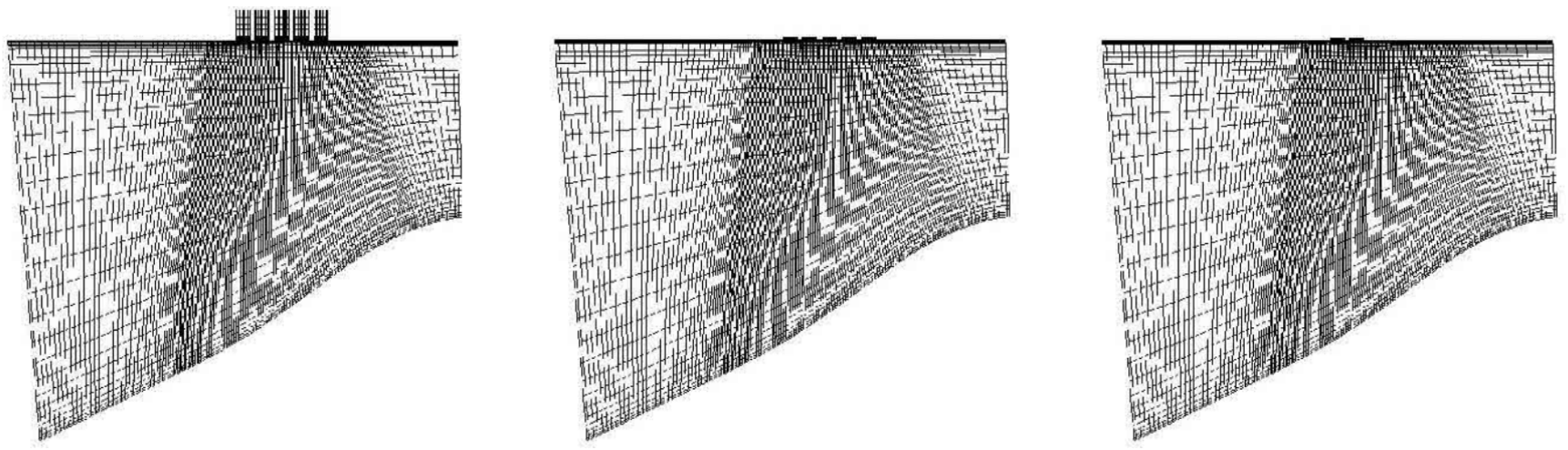

Figure 1: Three circumferential grooves configuration.

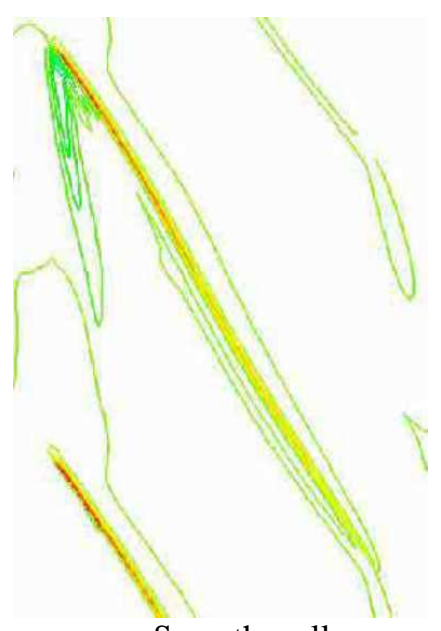

Smooth wall

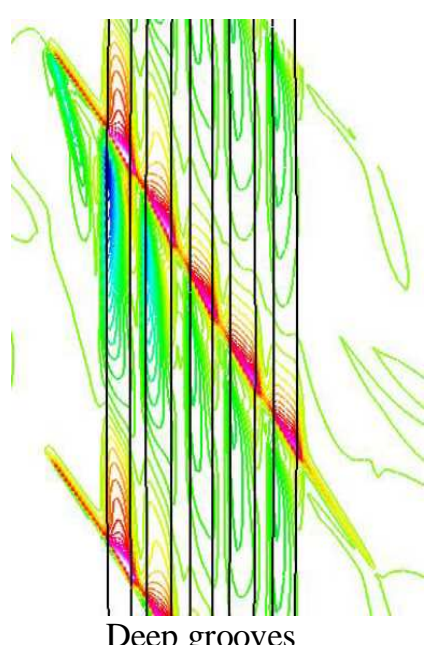

Deep grooves

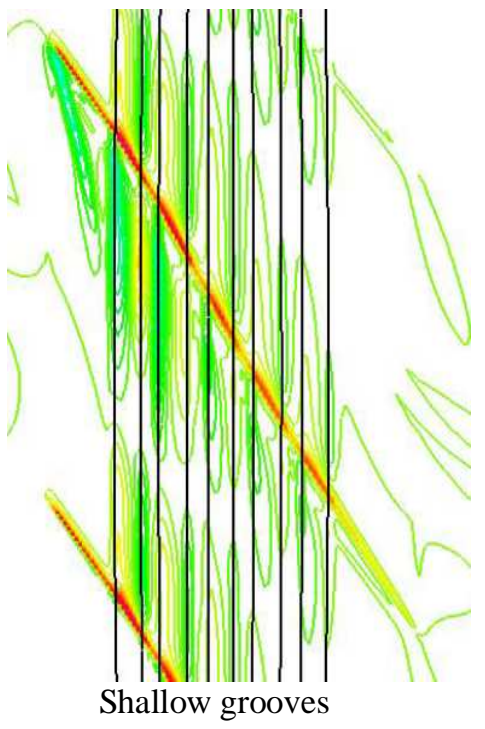

Figure 2 : radial velocity contours just below the casing 


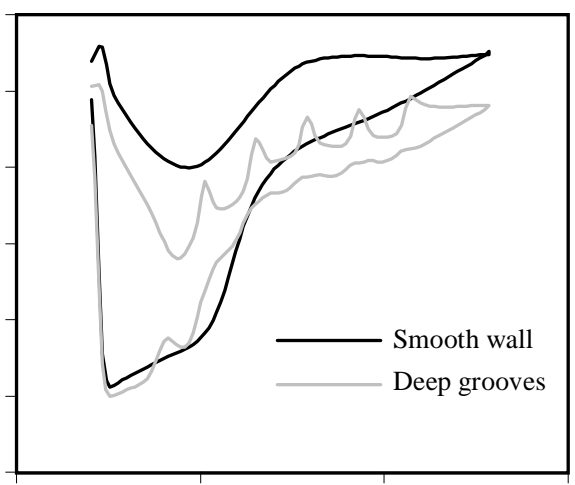

Figure 3 Changes in blade tip loading.

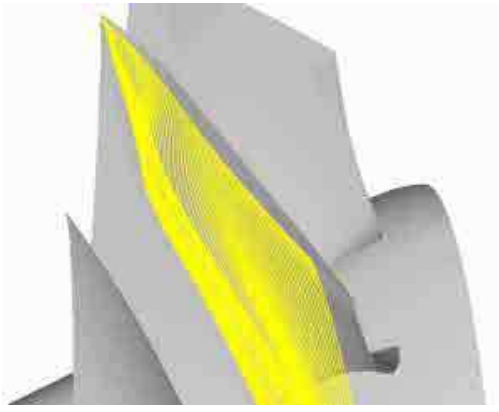

Smooth wall

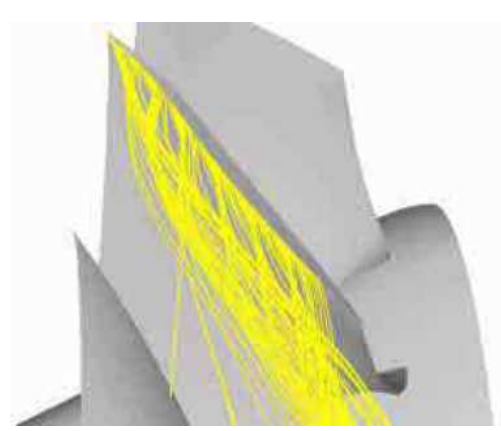

Deep grooves

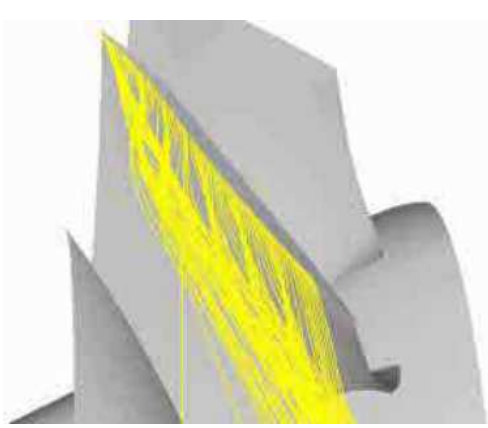

Shallow grooves

Figure 4 Tip clearance vortex structure.

Table 2 Darmstadt rotor design parameters.

\begin{tabular}{|l|c|}
\hline Pressure ratio & 1.5 \\
\hline Corrected mass flow rate & $16.0 \mathrm{~kg} / \mathrm{s}$ \\
\hline Corrected tip speed & $398 \mathrm{~m} / \mathrm{s}$ \\
\hline Inlet relative Mach number at tip & 1.35 \\
\hline Inlet relative Mach number at hub & 0.70 \\
\hline Shaft speed & $20,000 \mathrm{rpm}$ \\
\hline Tip diameter & $0.38 \mathrm{~m}$ \\
\hline Rotor mean aspect ratio & 0.94 \\
\hline Rotor solidity (hub/mid/tip) & $1.9 / 1.5 / 1.2$ \\
\hline
\end{tabular}

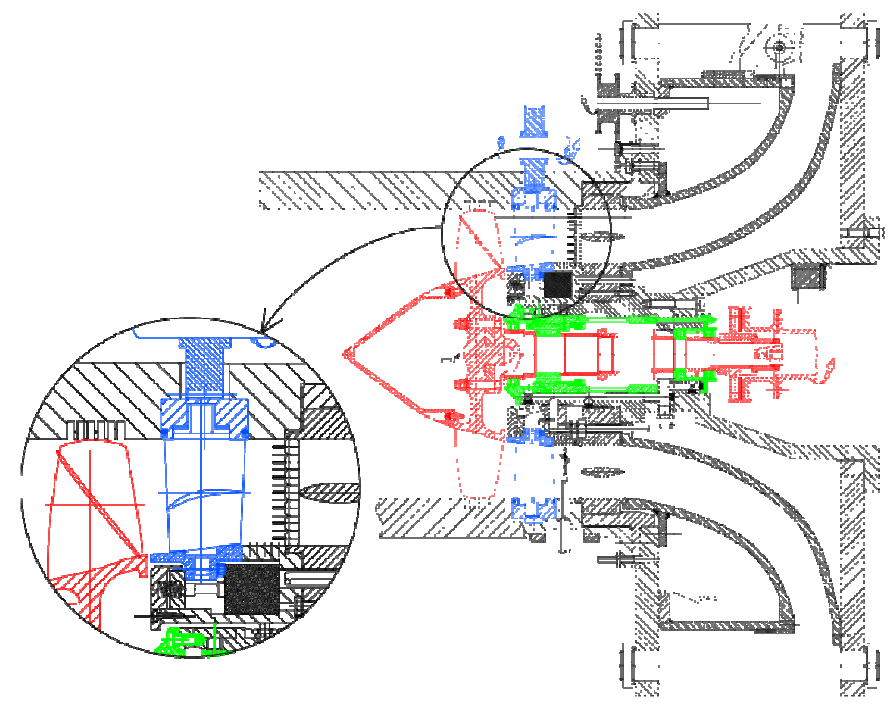

Figure 5 Darmstadt transonic compressor stage with circumferential casing grooves. 


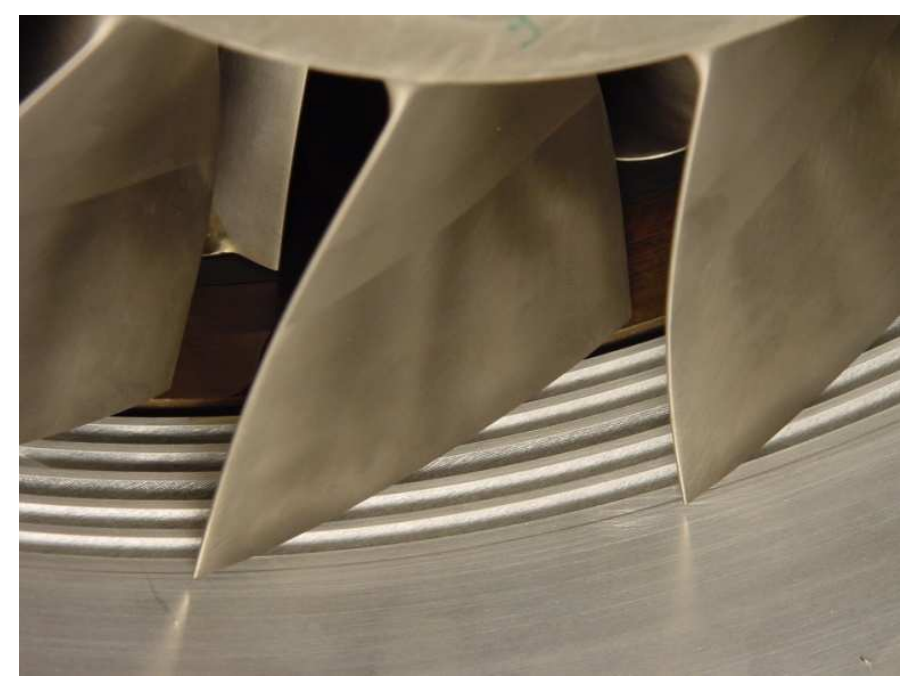

Figure 6 Casing treatment with six deep grooves.

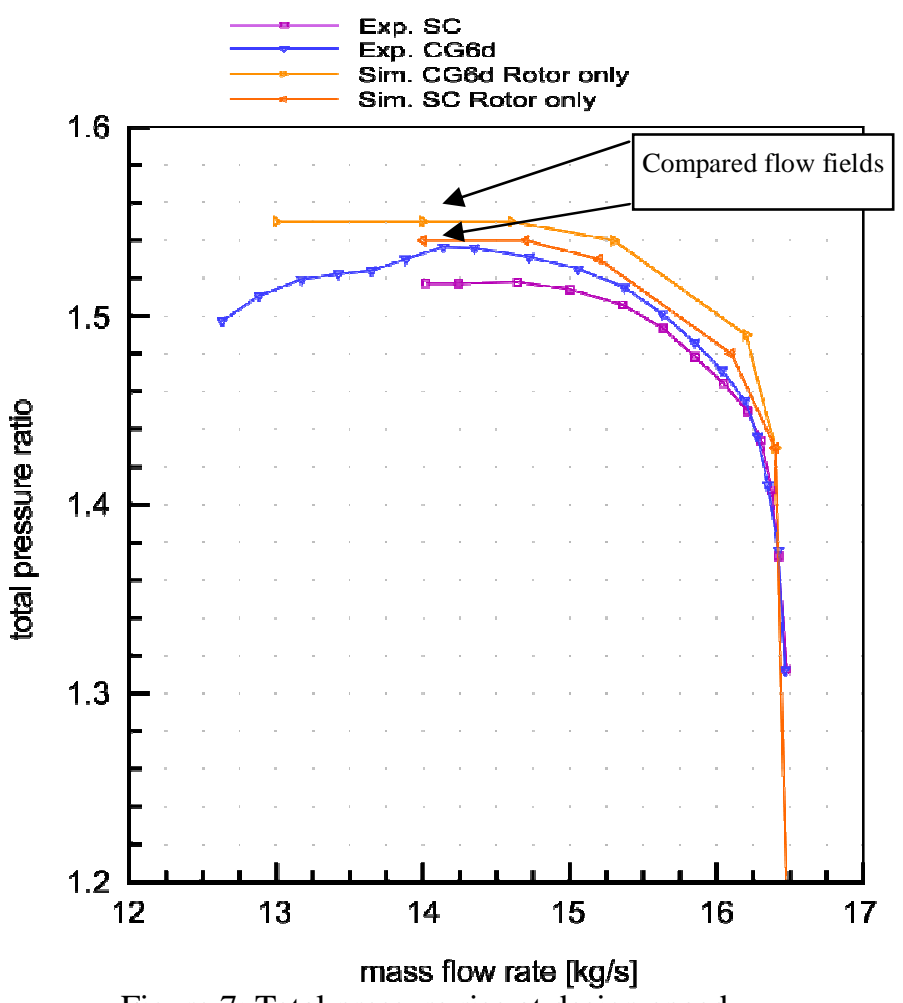

Figure 7: Total pressure rise at design speed.
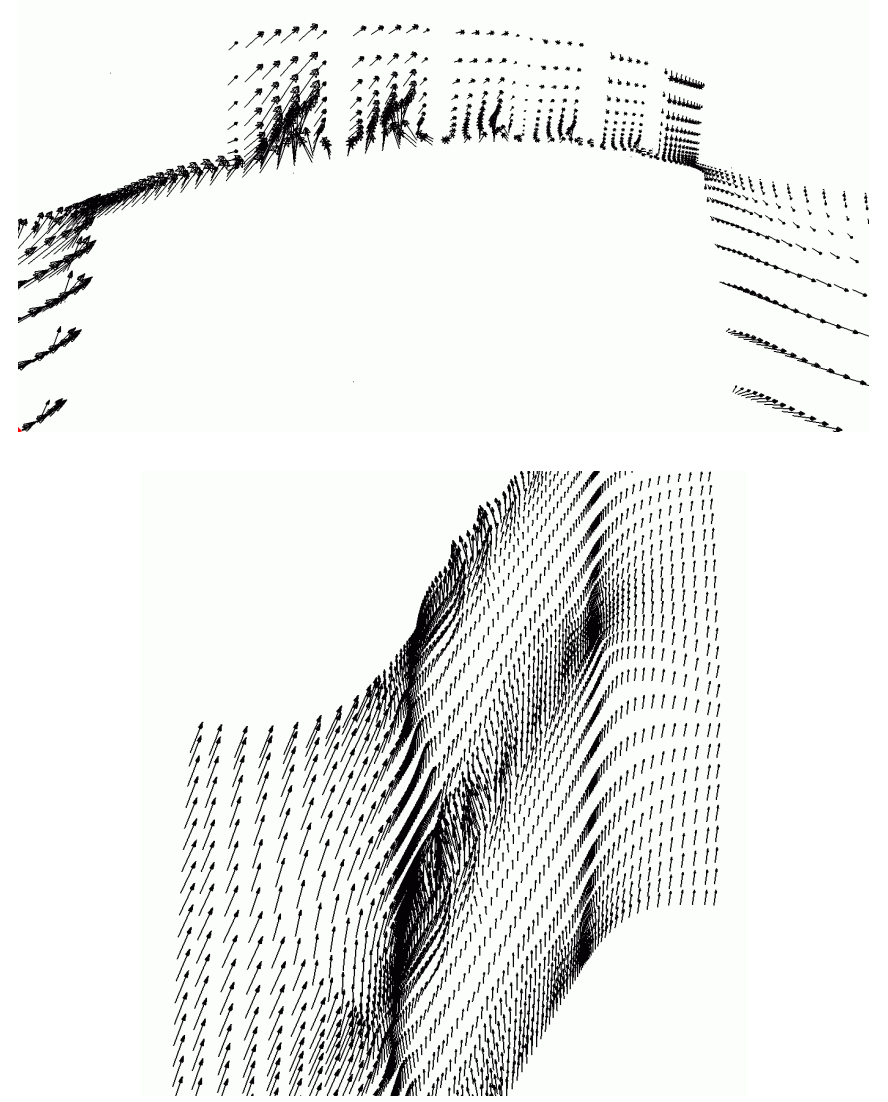

Figure 8 Calculated velocity vectors with 6 deep groves at the mass flow rate of $14 \mathrm{Kg} / \mathrm{sec}$.

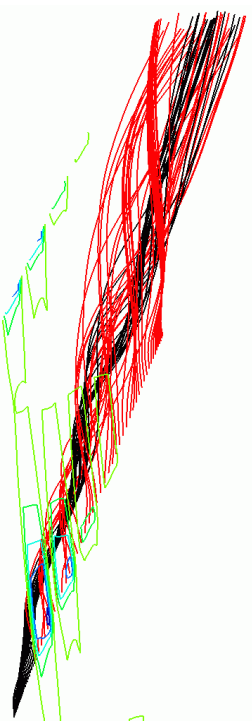

Figure 9 Tip clearance vortex structure with 6 deep grooves, mass flow rate of $14 \mathrm{Kg} / \mathrm{sec}$. 


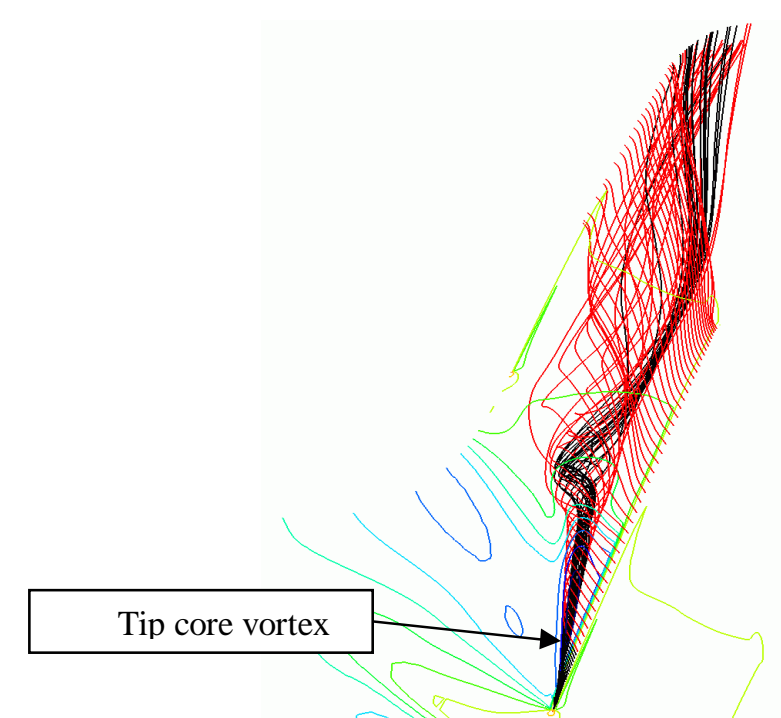

Figure 10 Tip clearance vortex structure with smooth casing, mass flow rate of $14 \mathrm{Kg} / \mathrm{sec}$.

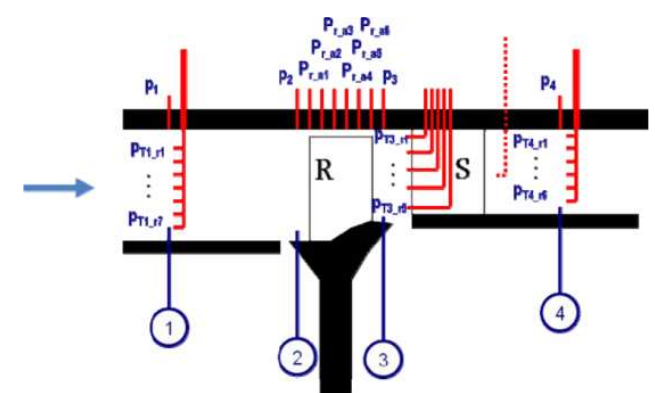

Figure 11 Notre Dame compressor stage (from Chen et al.[2010]).

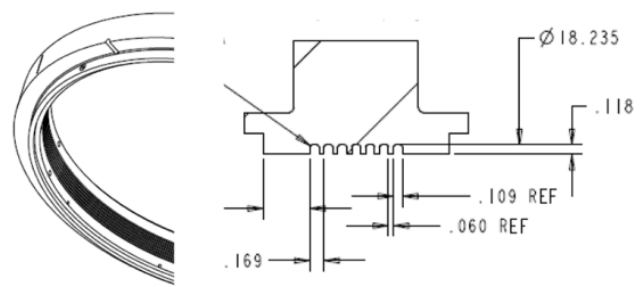

Figure 12 casing with 7 circumferential grooves.

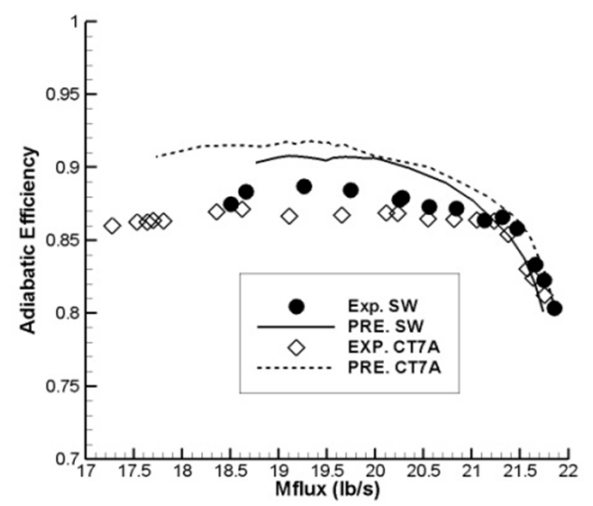

Figure 13 Comparison of adiabatic efficiency (from Chen et al. [2010).

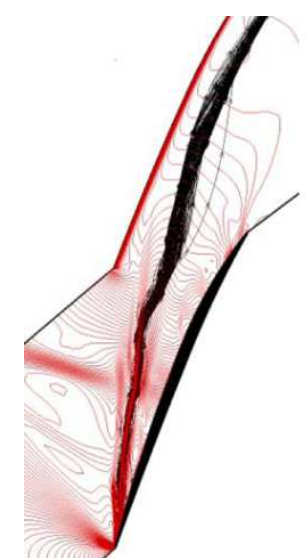

(a) $\mathrm{SW}$

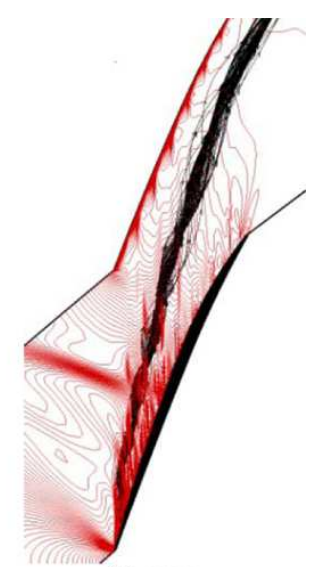

(b) CT7A

Figure 14 Comparison of tip clearance vortex structure (from Chen et al. [2010]).

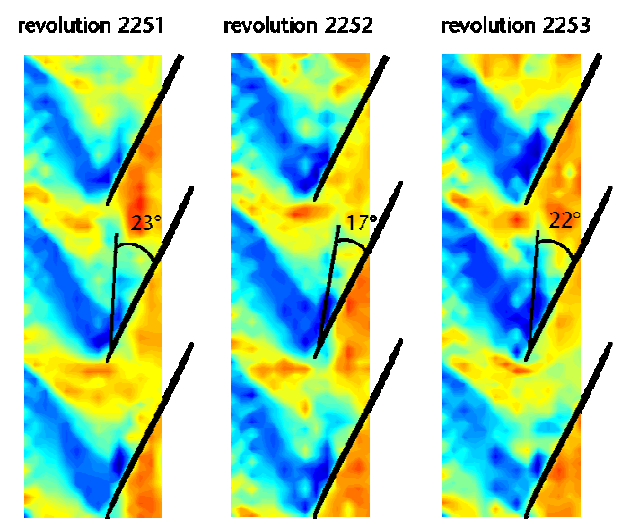

Figure 15 Instantaneous static pressure distribution at the casing with smooth wall.

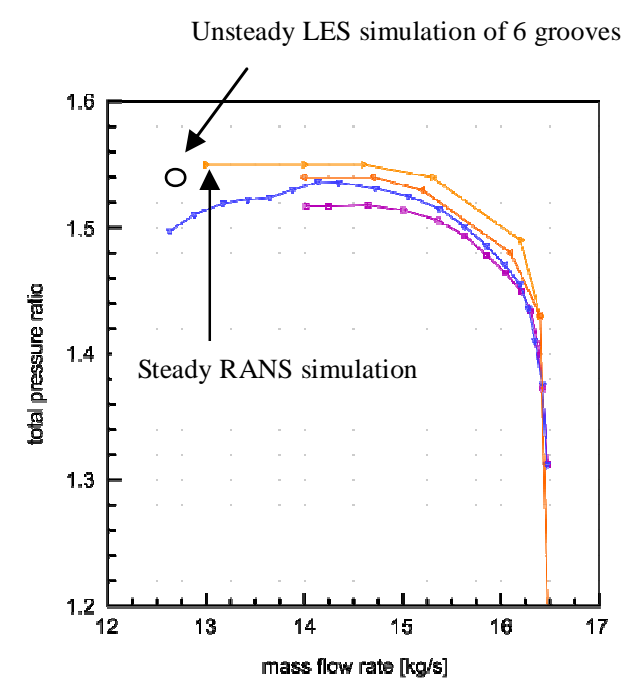

Figure 16 comparison of total pressure rise. 

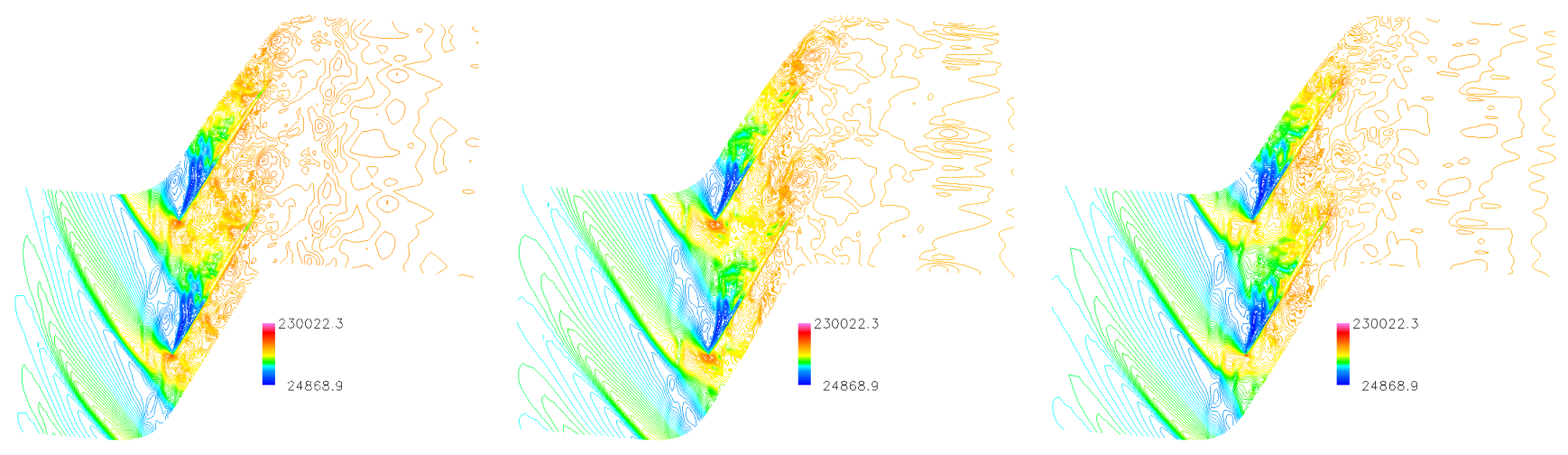

Figure 17 Calculated changes in static pressure at the blade tip
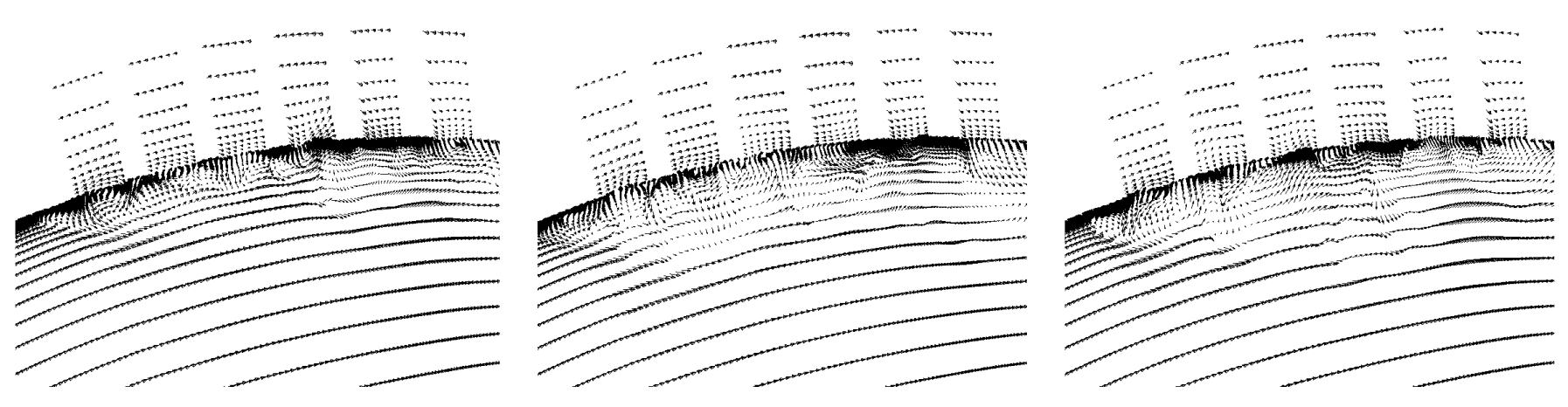

Figure 18 Instantaneous velocity vectors near the casing at $10 \%$ pitch from the pressure side. 

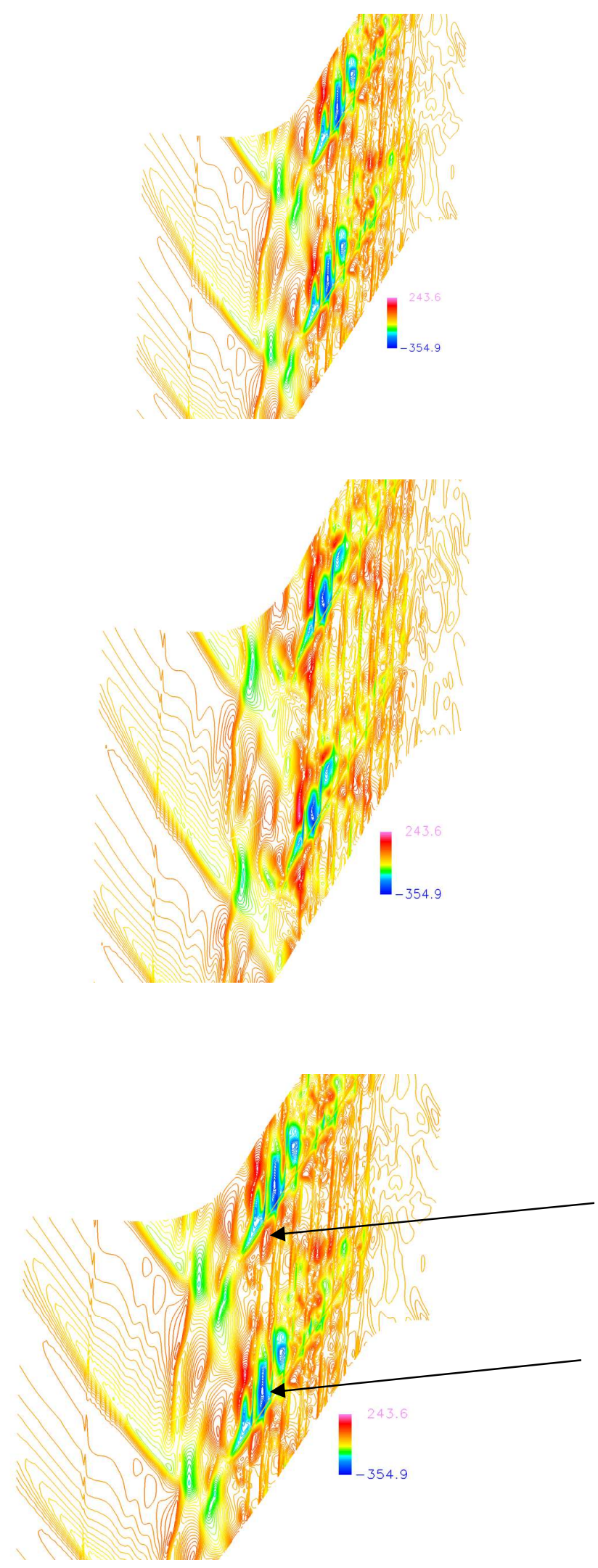

Flow bleeding into grooves

Flow impingement into main passage from grooves

Figure 19 Changes in radial velocity component just below compressor casing 